\title{
Do MTHFR C677T Genetic Polymorphism Influence in the Pathogenesis of Amyotrophic Lateral Sclerosis?
}

Rômulo Morais Azevedo

Universidade Federal de Goias

Kamilla de Faria Santos

Universidade Federal de Goias

Rayana Pereira Dantas de Oliveira

Universidade Federal de Goias

Júllia Costa Pereira

Universidade Federal de Goias

Dhiogo da Cruz Pereira Bento

Universidade Federal de Goias

Angela Adamski da Silva Reis

Universidade Federal de Goias

Rodrigo da Silva Santos ( $\nabla$ rdssantos@ufg.br)

Universidade Federal de Goiás https://orcid.org/0000-0002-9480-4362

\section{Research Article}

Keywords: Neurodegenerative disease, Genetic polymorphism, Biomarker, MTHFR, Personalized medicine

Posted Date: October 1st, 2021

DOl: https://doi.org/10.21203/rs.3.rs-939291/v1

License: (c) (i) This work is licensed under a Creative Commons Attribution 4.0 International License.

Read Full License 


\section{Abstract}

Amyotrophic Lateral Sclerosis (ALS) is a progressive and lethal neurodegenerative disease without a definitive diagnostic test and effective treatment. A plethora of studies suggest that genetic factors play an important role in ALS development, and potentially link folate pathway dysregulation to disease pathogenesis. This study aims to evaluate folate dysregulation due to MTHFR C677T polymorphism and other factors such as sociodemographic and clinical, to better elucidate the involvement of these factors in ALS pathogenesis, and to investigate possible biomarkers for use as disease diagnostics or prognostics. This hospital-based case-control study analyzed 101 patients diagnosed with ALS and 119 considered healthy, with no suspicion or diagnosis of neurodegenerative disease. Blood samples were collected, stored, and underwent DNA extraction. Clinical and sociodemographic data from patients were collected through a questionnaire, as well as consultation of medical records. Genotypic analyses were performed using PCR-RFLP, and statistical analysis of clinical and genotypic data was conducted with SPSS software, version 23. The results show a higher presence of the mutant genotype $(p=0.02)$ in the case group, and suggest that mutant allele $(T)$ is a risk factor for ALS susceptibility $(O R=1.54 ; 95 \% \mathrm{Cl}=$ $1.05-2.29 ; p=0.03$ ). Mutant genotype $(T / T)$ interacts with both demographics (White $p=0.005$ / Brown $p=0,001$ ) and clinical factors (Physical activity $p=0.006$ ) as risk factors for ALS. Also, a significant difference in alcohol consumption $(p=0.001)$ between the case and control group was observed. Moreover, a statistical trend towards faster disease progression and death was observed for patients with the mutant allele $(T)(p=0.06)$. Thus, the results of this study suggest that folate deficiency due to MTHFR C677T polymorphism is implicated in ALS through pathogenic mechanisms and interaction with other risk factors, resulting in faster disease progression and early death.

\section{Introduction}

Amyotrophic Lateral Sclerosis (ALS) is a lethal and progressive neurodegenerative disease that selectively affects the upper and lower motor neurons. It is characterized by symptoms such as cramps, fasciculations, muscle weakness and atrophy, dysphagia, dysarthria, and respiratory failure, which is the leading cause of death [1-3]. The disease has an annual incidence of about 1.55-1.96 / 100,000 inhabitants and a prevalence of 5.2-6.2 / 100,000 inhabitants, predominantly affecting individuals aged 55 to 75 years, Caucasian populations, and males $[4,5]$.

The causes of disease development are still undefined. ALS is thought to be a multifactorial pathology, associated with smoking, alcoholism, prolonged physical activities, and genetic factors $[6,7]$. There is ample evidence that genetic factors contribute to ALS susceptibility, and several genes have already been implicated in the neurodegenerative process, such as SOD1, VAPB, C9orf72, FUS, NEK1, TRPM7, and others $[8,9]$. Despite the continued discovery of an increasing number of genetic biomarkers in ALS, over $50 \%$ of patients do not have a genetic diagnosis [10].

Without a specific diagnostic test for the disease, ALS diagnosis is currently performed through clinical evaluation aided by neuroimaging and electroneuromyography tests [11]. The average time for the 
diagnosis is estimated to be nine months to one year, from the symptom onset $[12,13]$. Riluzole, a glutamate antagonist, is currently the only medicine with proven efficacy in improving ALS survival, but it only increases life expectancy by two to three months. It is known that early diagnosis associated with drug therapy using riluzole may enhance its efficacy in clinical improvement $[14,15]$.

Variation in genes involved in the folate pathway has been suggested as a possible factor implicated in ALS since this vitamin is essential to DNA synthesis and homocysteine (Hcy) metabolism, the dysregulation folate metabolism unbalances the cellular homeostasis, and could contribute to neurodegenerative processes in motor neurons $[16,17]$. The Methylenetetrahydrofolate reductase (MTHFR) gene stands out as a potential target, considering that it is responsible for encoding the MTHFR enzyme, which plays a crucial role in intracellular folate metabolism [18]. MTHFR enzyme regulates the intracellular methylation pathway and influences DNA synthesis by converting 5,10methylenetetrahydrofolate (5,10-MTHF) into 5-methyltetrahydrofolate (5-MTHF), the most abundant circulating form of folic acid in the body [18-22].

It is known that polymorphisms in the MTHFR gene result in the production of a defective enzyme, which deregulates the entire intracellular biochemical process of folate. Among the main polymorphisms studied in the gene, the C677T (rs1801133) mutation codes for a thermolabile enzyme with reduced activity by up to $65 \%$ at $35{ }^{\circ} \mathrm{C}$, resulting in increased plasma levels of Hcy $[23,24]$. The mutation has been identified as a risk factor for several diseases, such as cardiovascular diseases [25, 26], cancers [27, 28], diabetes [29], hypertension [30], and congenital malformations [31].

In the nervous system, dysregulation of the folate cycle directly impacts neuronal physiology by causing hyperhomocysteinemia (HHcy). Homocysteine is a neurotoxic factor and is associated with several neuronal death mechanisms [32,33]. Thus, increasing numbers of studies have hypothesized the folate metabolic dysfunctions in ALS pathogenesis, especially after the detection of HHcy in ALS patients affected by the disease and the discovery of its effect on the motor neuron [34, 35].

Therefore, this study aims to evaluate the MTHFR C677T polymorphism, socio-demographic and clinical factors in ALS patients in the population of central Brazil, to understand how genetic causes of intracellular folate dysregulation, as well the influences of environmental and clinical factor affect disease susceptibility and progression.

\section{Material And Methods}

\section{Population study (Patients)}

This hospital-based case-control study consists of 101 patients diagnosed with ALS (case group) who underwent medical follow-up at the referral hospital for neuromuscular diseases in Goiânia, GO, Brazil, Dr. Henrique Santillo Rehabilitation and Readaptation Center (CRER). The control group consists of 119 individuals not diagnosed with ALS or other neurodegenerative diseases, collected from the Laboratory of Clinical Analysis and Health Education of the Federal University of Goiás, Brazil (LACES-UFG). 
We selected patients with a minimum age of 18 years and a maximum of 90 years, regardless of the stage of disease progression, who followed the protocol of laboratory and imaging tests defined for the disease diagnosis, standardized by the CRER. Patients unable to give venous blood samples were excluded.

Patients who agreed to participate signed the Informed Consent Form (ICF) and completed a questionnaire concerning age, gender, ethnicity, physical activity, occupation, smoking, and alcohol consumption. The groups were matched for gender and age according to the Strengthening the Reporting of Observational Studies in Epidemiology (STROBE) and STrengthening the REporting of Genetic Association studies (STREGA) guidelines [36].

Regarding the lifestyle questions, patients who reported smoking for more than one year were considered smokers. Likewise, patients who reported regularly consuming alcohol for at least one year before their ALS diagnosis were considered consumers of alcohol. Also, in the case group, medical records were consulted to obtain clinical information, such as disease classifications, symptoms, treatments, and outcomes.

\section{Ethical Principles}

The study was conducted with the assent of the Research Ethical Committee from the Federal University of Goiás, Brazil (CEP/UFG) under protocol number CAAE 79593117.7.0000.5083, and also followed the Ethical Principles for Medical Research Involving Humans of the Declaration of the World Medical Association of Helsinki.

\section{Sample Collection and Analysis for MTHFR C677T Polymorphism}

The peripheral blood samples from the patients were collected using a venous puncture technique in $4 \mathrm{ml}$ tubes containing an anticoagulant (EDTA) identified and processed at $5000 \mathrm{rpm}$ for ten minutes. Then, the samples were subjected to DNA extraction and purification with a commercial kit (Invitrogen ${ }^{\circledR}$ ) using the protocol suggested by the manufacturer. The extracted samples were identified and stored at $-80^{\circ} \mathrm{C}$, and subsequently subjected to genomic material quantification evaluation using the NanoDrop ${ }^{\mathrm{TM}} \mathrm{ND}$ 1000 spectrophotometer (ThermoFisher ${ }^{\circledR}$, USA).

Genotypic analyses for the MTHFR C677T polymorphism were performed at the Laboratory of Molecular Pathology, Institute of Biological Sciences (ICB), Federal University of Goiás, Goiânia, GO, Brazil.

Polymerase Chain Reaction and Restriction Fragment Length Polymorphism (PCR-RFLP) analysis were employed. Thermocycling protocols were set as suggested [37]. Forward primer: 5'AGGCTGACCTGAAGCACTTGAA-3', Reverse primer: 3'-CTCAAAGAAAAGCTGCGTGATGA-'5.

PCR conditions were $94^{\circ} \mathrm{C}$ for 5 min of denaturation and 36 cycles of $61^{\circ} \mathrm{C}$ for $1 \mathrm{~min}, 72^{\circ} \mathrm{C}$ for 1 min 30 seconds, and $4{ }^{\circ} \mathrm{C}$ at the end. The Hinfl enzyme was used for digestion, and the resulting restriction fragments were visualized on a polyacrylamide gel (15\%), stained in $4 \mathrm{~g} / \mathrm{L}$ silver nitrate solution, allowing 
for the identification of wildtype genotypes (C/C) 198bp fragment, heterozygotes (C/T) 198bp, 175bp, and $23 \mathrm{bp}$ fragments, and mutants $(\mathrm{T} / \mathrm{T}) 175 \mathrm{bp}$ and $23 \mathrm{bp}$ fragments.

\section{Statistical analysis}

Statistical analysis was performed using the SPSS statistical package, version 23 . The general characterization of the case group and control group individuals was performed with descriptive statistics, with absolute ( $\mathrm{n}$ ) and relative (\%) frequencies reported, while mean and standard deviation were applied to continuous variables.

For genotypic analysis, PostHoc Chi-square tests and Pearson's test (MacDonald and Gardner, 2000) were performed. To study survival (time between ALS diagnosis and death) according to genotype, KaplanMeier curves were created. For all results, a significance level of $5 \%$ was used.

\section{Results}

\section{Sociodemographic and clinical data}

Sociodemographic data were evaluated for ALS (101 individuals) and control (119 individuals) groups. Mean ages were $57.3 \pm 12.8$ years for the case group and $58.0 \pm 10.3$ years for the control group (Table 1).

The case group had $44.6 \%$ of female patients (45 individuals) and $55.4 \%$ of male patients (56 individuals). In the control group, $57.1 \%$ were female (68 individuals), and $42.9 \%$ were male (51 individuals $)$. Age $(p=0.64)$ and gender $(p=0.08)$ showed no statistically significant associations with the disease.

In the analysis of risk factors, smoking was not different between the case and control groups $(p=0.28)$. However, alcohol consumption was higher in the case group than in the control group $(p=0.01)$, therefore, it is a possible risk condition for the disease among the studied groups (Table 1).

Table 1 - Comparison of clinical and sociodemographic variables between case and control group. 


\begin{tabular}{|c|c|c|}
\hline $\begin{array}{l}\text { Control } \\
(54.1)\end{array}$ & 119 & $\begin{array}{l}\text { Case } \\
(45.9)\end{array}$ \\
\hline
\end{tabular}

\begin{tabular}{|c|c|c|c|}
\hline $\begin{array}{l}\text { Age (Mean } \pm \\
\text { SD) }\end{array}$ & $58.0 \pm 10.3$ & $57.3 \pm 12.8$ & $0.64^{\star \star}$ \\
\hline
\end{tabular}

\section{Gender}

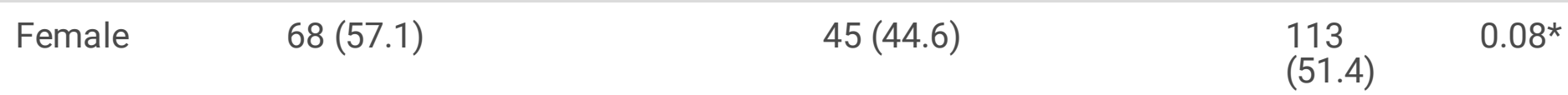

$\begin{array}{lll}\text { Male } 51(42.9) & 56(55.4) & 107 \\ & & (48.6)\end{array}$

\begin{tabular}{llcll} 
Alcohol Intake & & & \\
& & & \\
No & $84(70.6)$ & $55(54.5)$ & 139 & $0.01^{*}+$ \\
Yes & $35(29.4)$ & $46(45.5)$ & $81(36.8)$ & \\
\hline
\end{tabular}

\section{Smoking}

$\begin{array}{llll}\text { No } & 68(57.1) & 65(64.4) & 133 \\ \text { Yes } & 51(42.9) & 36(35.6) & 80.58^{*}\end{array}$

*Pearson's Chi-square test, $* \star$ Student t-test, $\uparrow p<0,05$.

$\mathrm{n}=$ absolute frequency, $\%$ = relative frequency

SD = standard deviation, ALS- Amyotrophic Lateral Sclerosis,

In the ALS group, $48.5 \%$ identified as white and $44.6 \%$ identified as brown. When asked about physical activity, $46.5 \%$ declared that they did not engage in any type of physical activity before the diagnosis of the disease, while $53.5 \%$ reported physical activity. The reported physical activities included walking, soccer, water aerobics, workout, pilates, and others. Most cases reported work in the following categories: general service category (36.6\%), housework (13.9\%), administrative services $(12.9 \%)$, commerce $(9.9 \%)$, teachers (7.9\%), health professional (5.9\%), chef cook (1\%), student (1\%), and others (5\%). However, $5.9 \%$ chose not to inform.

The patients in the case group were classified according to the El Escorial World Federation of Neurology, as reported in their medical records. $5.9 \%$ of patients reported a recurrence of ALS in the family (fALS), and $94.1 \%$ were considered sporadic cases (sALS). Moreover, $72.3 \%$ fit the cALS category, $23.8 \%$ were bALS, and $4 \%$ were juvenile ALS. Previous pathologies were cited by $46.5 \%$ in the case group, and $40.6 \%$ reported a history of another neurological disease in the family. 
Regarding treatment with riluzole, $75.2 \%$ of the case group said they followed the treatment, and $24.8 \%$ reported not using it. During the research period, $10.9 \%$ of the ALS patients in the case group died.

Therefore, death was considered as a disease outcome in this study.

\section{Genotypic data and association with risk factors}

According to the genotypic analysis, the mutant genotype $(T / T)$ was more frequent in patients diagnosed with ALS than in the control group, representing $9.9 \%$ and $2.5 \%$ of the groups, respectively $(p=0.02)$.

Allelic evaluation corroborates the genotypic analysis, showing that the frequency of the T allele is a higher risk for the development of the disease than the $C$ allele $(O R=1.54,95 \% \mathrm{Cl}=1.05-2.29)(p=0.03)$, shown in Table 2.

Table 2 - Association of MTHFR C677T genotype and allele frequency with ALS.

MTHFR C677T Samples $\mathrm{n}(\%) \quad$ Total Odds Ratio $\quad p$

$\begin{array}{lr}\text { Control } & \text { Case } \\ 119(54.1) & 101(45.9)\end{array}$

$(95 \% \mathrm{Cl})$

\section{Genotypic \\ Frequency}

\begin{tabular}{llllll} 
Wild (C/C) & $61(51.3)$ & $41(40.6)$ & $\begin{array}{l}102 \\
(46.4)\end{array}$ & Reference & $0.11^{\star *}$ \\
\hline $\begin{array}{l}\text { Heterozygous } \\
(\mathrm{C} / \mathrm{T})\end{array}$ & $55(46.2)$ & $50(49.5)$ & $\begin{array}{l}105 \\
(47.7)\end{array}$ & $0.85(0.51-1.41)$ & $0.63^{\star *}$ \\
\hline Mutant $(\mathrm{T} / \mathrm{T})$ & $3(2.5)$ & $10(9.9)$ & $\begin{array}{l}13 \\
(5.9)\end{array}$ & $1.83(1.27-2.65)$ & $0.02^{\star *}$
\end{tabular}

\section{Allele}

Frequency

\begin{tabular}{|c|c|c|c|c|}
\hline $\mathrm{C}$ & $219(74.5)$ & $132(65.3)$ & $\begin{array}{l}351 \\
(70.8)\end{array}$ & Reference \\
\hline $\mathrm{T}$ & 75 (25.5) & 70 (34.7) & $\begin{array}{l}145 \\
(29.2)\end{array}$ & $1.54(1.05-2.29)$ \\
\hline
\end{tabular}

* Pearson's Chi-square test, $* \star$ Post hoc Chi-square, $\dagger p<0,05$.

$\mathrm{n}=$ absolute frequency, \% = relative frequency

ALS - Amyotrophic Lateral Sclerosis.

These results suggest a possible association of MTHFR C677T polymorphism with ALS, which could be due to dysregulation of the folate metabolism, leading to increased plasma Hcy levels, alterations in DNA synthesis, RNA and protein hypomethylation, oxidative stress, neuroinflammation, and ultimately the death of motor neurons (Fig. 1). 
When analyzing associations of clinical data with the results of the genotypic analysis of ALS patients, the patients' gender $(p=0.85)$, alcohol intake $(p=0.16)$, smoking $(p=0.42)$, disease classification $(p=$ $0.57)$, neurological disease in the family $(p=0.99)$, and previous pathologies $(p=0.90)$ did not present a statistically significant association with genotype in disease development (Table 3). However, ethnicity, when compared with genotypic profile, was significantly associated with $(T / T)$ genotype patients, specifically for self-identified white $(p=0.005)$ and brown $(p=0.001)$ individuals. Engaging in physical activity was also associated with the $(T / T)$ genotype $(p=0.006)$, shown in Table 3 .

Table 3 - Association between MTHFR C677T polymorphism genotype with the demographic and clinical profile of ALS patients. 
Wild Heterozygous Mutant

\section{Gender}

\begin{tabular}{lllll} 
Female & $19(46.3)$ & $21(42.0)$ & $5(50.0)$ & 0.85 \\
\cline { 1 - 3 } Male & $22(53.7)$ & $29(58.0)$ & $5(50.0)$ &
\end{tabular}

\section{Ethnicity}

\begin{tabular}{lllll} 
White & $20(48.8)$ & $28(56.0)$ & $1(10.0) \dagger$ & 0.005 \\
\hline Black & $6(14.6)$ & $1(2.0)$ & $0(0.0)$ & 0.23 \\
\hline Brown & $15(36.6)$ & $21(42.0)$ & $9(90.0) \dagger$ & 0.001
\end{tabular}

\section{Physical Activity}

$\begin{array}{lllll}\text { No } & 23(56.1) & 24(48.0) & 0(0.0) & 0.006 \\ \text { Yes } & 18(43.9) & 26(52.0) & 10(100.0) \dagger & \end{array}$

Alcohol Intake

$\begin{array}{lllll}\text { No } & 27(65.9) & 23(46.0) & 5(50.0) & 0.16 \\ \text { Yes } & 14(34.1) & 27(54.0) & 5(50.0) & \end{array}$

\section{Smoking}

$\begin{array}{lllll}\text { No } & 29(70.7) & 29(58.0) & 7(70.0) & 0.42 \\ \text { Yes } & 12(29.3) & 21(42.0) & 3(30.0) & \end{array}$

\section{Classification}

\begin{tabular}{lllll}
\cline { 1 - 2 } Sporadic & $39(95.1)$ & $46(92.0)$ & $10(100.0)$ & 0.57 \\
\cline { 1 - 3 } Familial & $2(4.9)$ & $4(8.0)$ & $0(0.0)$ &
\end{tabular}

\section{Neurological disease in the Family}

\begin{tabular}{lllll} 
No & $24(58.5)$ & $30(60.0)$ & $6(60.0)$ & 0.99 \\
\cline { 1 - 3 } Yes & $17(41.5)$ & $20(40.0)$ & $4(40.0)$ &
\end{tabular}

\section{Previous pathologies}

\begin{tabular}{lllll} 
No & $23(56.1)$ & $26(52.0)$ & $5(50.0)$ & 0.90 \\
\cline { 1 - 3 } Yes & $18(43.9)$ & $24(48.0)$ & $5(50.0)$ &
\end{tabular}

* Post hoc Chi-square, $+p<0,05, \mathrm{n}=$ absolute frequency, \% = relative frequency. 


\section{Association of genotypic profile and ALS outcome}

Survival analysis was performed with the onset of symptoms as the starting point and death as the outcome according to the MTHFR C667T polymorphism genotypes. This analysis demonstrated a statistical trend towards more significant progression and earlier death of patients with the heterozygous genotype $(C / T)$ when compared to $(C / C)$ patients $(p=0.06)$, presented in Fig. 2.

\section{Discussion}

ALS is a heterogeneous disease with ethnic and sociodemographic differences. In this study, the ALS group has an average age of $57.3 \pm 12.8$ years, younger patients represent $4 \%$ of the group, and $55.4 \%$ are males. ALS disease affects mainly men, with a male-to-female ratio between 1 and 2, and the initial symptoms usually manifest between $55-75$ years $[2,7,38]$. Despite the prevalence in the elderly, young people with an average age of 20 years are also affected, representing $1-10 \%$ of all cases, classified as juvenile ALS [39]. In this study, the average age and gender proportions in the case group correspond to the literature [40]. However, age and gender are not significantly different between groups (Table 1).

The reason for the difference in occurrence between the genders is not yet known. Some studies associate a lower prevalence of ALS in women with a hormonal protective effect or lower exposure to risk factors $[41,42]$. Recent studies suggest that estrogen acts as a protective factor in neurodegenerative processes by countering mechanisms of oxidative stress and excitotoxicity [43-45]. Despite the lower incidence of women among ALS patients in general, they are more associated with a disease-specific classification, the FTD-ALS cases, which has been justified by genetic factors [46]. However, further studies are needed to elucidate gender biases in ALS.

Looking at the sociodemographic make-up of the case group, white people comprised the most substantial proportion, representing $48.5 \%$ of the individuals, and $44.6 \%$ were brown. These results corroborate other studies that report a higher incidence of the disease in white populations, which has been associated with genetic factors $[5,47]$. Besides, the white population has more easy access to health programs than the black population, traditionally considered a minority in a society that often neglects social rights [48].

Among the modifiable variables analyzed, alcohol consumption as a risk factor for ALS is still controversial. Some studies show the consumption of alcohol as a protective factor for the disease [49, 50]. However, in the present study, alcohol consumption was more reported in the case group; thus, it is a possible risk condition for the disease $(p=0.01)$. Such a hypothesis does have a potential mechanistic explanation. Excessive alcohol consumption increases the sensitivity of glutamate receptors and increases the concentration of glutamate in the central nervous system, leading to excitotoxicity and neuronal death [51]. Additionally, it is known that alcohol consumption can activate astrocytes through alterations in proteins expressed in microglia, implying in neuroinflammatory mechanisms [52]. 
Smoking as a risk factor for ALS is also controversial. Some studies relate smoking to an increased risk for the disease, possibly linked to the toxic effects of cigarette substances $[49,53]$. Smoking results in neuronal death since nicotine interacts with acetylcholine receptors in the central nervous system, causing the dysregulation of $\mathrm{Ca}^{2+}, \mathrm{Na}^{+}$, and $\mathrm{K}^{+}$ion concentrations, increased cell permeability, oxidative stress, and neuroinflammation [54,55]. Nevertheless, there was no statistically significant difference in identification as a smoker between the groups in this study $(p=0.28)$.

Other factors were investigated in the case group, such as physical activity and occupation before the diagnosis of ALS. Some studies indicate that physical activity could contribute to the risk of disease development, as it results in increased metabolic rates in the body, which is related to the production of reactive oxygen species and oxidative stress $[56,57]$. In this sense, the hypermetabolic condition was reported as a characteristic of ALS pathogenesis, and it has been discussed as a determining factor in neurodegenerative processes $[58,59]$. Besides, physical activity has been associated with neuronal death, due to its relation to the increase of pro-inflammatory cytokine expression resulting in neuroinflammation processes. Additionally, it is known that physical injuries during such practices may contribute to the genesis of the pathological process $[57,60]$. In the present study, physical activity was reported by most ALS individuals, representing $53.5 \%$ in the case group (Table 3 ). Similar results were found in studies by [57] and [61].

In the professional occupation analysis of the ALS group, most individuals reported working in professions that require physical exertion or repetitive activities, like general services (36.6\%), housework (13.9\%), administrative services $(12.9 \%)$, commerce $(9.9 \%)$, teachers $(7.9 \%)$, and health professionals $(5.9 \%)$. In general, activities in which professionals are exposed to chemicals and require significant physical performance are considered risk factors for ALS $[62,63]$. The present study corroborates the literature regarding occupational exposure, in which professions such as health professionals, teachers, scientists, and athletes are most affected by the disease $[64,65]$. However, further research is needed on the association of occupational factors and clinical factors with disease susceptibility.

ALS patients were also classified into major disease variations according to the recommendations of the El Escorial World Federation of Neurology and information contained in medical records. We observed a higher percentage of sALS (94.7\%) and fALS (5.9\%). Moreover, $72.3 \%$ fit into the cALS category, $23.8 \%$ were bALS, and $4 \%$ were juvenile cases. These data corroborate the prevalence of the classifications described in the literature, where sALS represents 90 to $95 \%$ of all ALS cases, and $\sim 5$ to $10 \%$ are fALS. The other classifications also follow the same pattern, in which the classical form of the disease is most prevalent $\sim 50$ to $75 \%$, the bulbar form affects $\sim 20$ to $25 \%$ of all cases, and juveniles vary from $\sim 1$ to $10 \%[3,39]$.

Also, in the case group, individuals were asked about their past medical history and cases of neurodegenerative diseases in the family. Research on patients' previous diseases and the occurrence of neurodegenerative diseases in the families of ALS patients has grown considerably in recent years due to the discovery of the common etiopathogenesis among some diseases, which aroused scientists'

Page $11 / 27$ 
attention to a better understanding of the mechanisms involved in ALS $[66,67]$. The present study showed that $46.5 \%$ of the patients in the case group reported some type of disease before the ALS diagnosis, and $40.6 \%$ reported cases of neurodegenerative diseases in the family. Significant results of neurological disease history in family and ALS were found in the studies by [66], [68] and [69].

Regarding drug treatment, $75.2 \%$ of ALS patients reported taking riluzole, and $24.8 \%$ reported not having followed the treatment. Riluzole is the only drug approved for ALS treatment in Brazil. Nevertheless, studies report no significant increase in patient survival attributed to this drug treatment - only about two to three months $[14,70]$. Other medications are currently being studied for ALS treatment, such as Edaravone (Radicut), Masitinib [14], Tirasemtiv [71], and others. However, the progressive character of the disease and the lack of effective medication contribute to the short life expectancy after the diagnosis, which varies between three and five years.

Concerning the genotyping analyses, this study demonstrates a higher prevalence of genotype $(T / T)$ in ALS patients, making it a possible risk factor for the disease $(\mathrm{OR}=1,83 ; 95 \% \mathrm{Cl}=1.27-2.65)(p=0.02)$. Similarly, the allele frequency analysis showed that the $T$ allele confers risk for disease susceptibility (OR $=1.54 ; 95 \% \mathrm{Cl}=1.05-2.29)(p=0.03)$ (Table 2). The same results were found in studies by [72] and [73].

The hypothesis that MTHFR C677T polymorphism may contribute to ALS pathogenesis is supported by evidence showing that this polymorphism causes an imbalance of the intracellular folate pathway [74], which is associated with several pathogenic mechanisms, such as hypomethylation, increased Hcy levels in the organism, and altered nucleotide synthesis. These mechanisms have been implicated in central nervous system malformation, cognitive impairment, depression, epilepsy, Down syndrome, and the development of neurodegenerative diseases $[75,76]$.

Intracellular folate dysregulation could be driven by several factors, especially alterations in genes acting on its biochemical pathway [23]. Remarkably, the MTHFR gene stands out due to its coding of the enzyme MTHFR, which plays a crucial role in folate intracellular metabolism by converting 5,10-MTHF into 5-MTHF, the main circulating form of folic acid and most abundant form in the body [77]. The enzyme MTHFR directly regulates the intracellular methylation cycle, since the 5-MTHF reduced by the enzyme is an intermediate necessary for the methylation of Hcy to produce methionine. Such a process is essential to cellular homeostasis, and vital to the synthesis of SAM, the main active molecule in folic acid intracellular methylation processes [24]. Also, the enzyme MTHFR indirectly influences purine synthesis via the Methylenetetrahydrofolate dehydrogenase (MTHFD) pathway through the use of the 5,10-MTHF molecule, which can be used in both pathways [21].

The MTHFR gene is more expressed in the brain, muscle, placenta, and stomach, possibly due to the greater need for folate homeostasis in these tissues [78]. More than 20 genetic variations in the gene are known to result in the coding of non-functional enzymes. Among these, the C677T single nucleotide polymorphism - SNP is the main alteration studied. Cytosine is replaced with thymine at position 677 in exon 4, causing the change in coding for the amino acid alanine to valine. This change results in the production of a thermolabile enzyme with activities reduced by $35 \%$ in the case of heterozygous $(C / T)$ 
and $65 \%$ in homozygous $(\mathrm{T} / \mathrm{T})$ at $35^{\circ} \mathrm{C}[22,24]$. Various diseases are associated with this production, such as cardiovascular disease [25, 26], diabetes [29], hypertension [30], congenital anomalies [31], cancers [27, 28], and neurodegenerative diseases such as Alzheimer $[79,80]$ and Parkinson $[81,82]$.

The C677T polymorphism directly interferes with the available concentration of 5-MTHF, a molecule that is used in the bioconversion of Hcy to methionine and is essential in the production of SAM [24]. Low SAM synthesis is a limiting factor in the methylation cycle, which is crucial for DNA interactions, chromatin structure, and transcription rates, all of which are involved in epigenetic mechanisms that are essential for neuronal development and differentiation [22, 83].

Epigenetic changes during embryonic development are known to result in life-long functional changes, predisposing individuals to various neurological disorders [22]. Although not well understood, some studies report that folate cycle dysregulation and epigenetic changes are associated with alterations in stem cell differentiation and proliferation rates of neurons, the formation of neuromuscular junctions, neural cell specialization, and decreased cells in cortical regions [74, 75, 84]. Thus, the importance of epigenetic changes for motor neurons should be considered, as they are highly differentiated with large prolongations in the central nervous system and responsible for specialized functions in the contraction of effector muscles in the periphery [85].

Furthermore, hypomethylation resulting from the MTHFR C677T polymorphism could be associated with ALS pathogenesis since it may affect proteins that compound the neuronal cytoskeleton such as tubulin, $\beta$-actin [86], myelin, and cell membrane phospholipids, thus supporting the neurodegenerative process through structural changes and demyelination of the nervous system [83, 87]. Moreover, disturbances in the methylation process are associated with lower synthesis of inhibitory neurotransmitters such as gamma-aminobutyric acid (GABA) and serotonin, which causes neuroplasticity dysregulation and exposes motor neurons to glutamate excitotoxicity in ALS [88-90].

Additionally, HHcy due to the MTHFR C677T polymorphism is known to affect cellular redox states, associated with higher production of reactive oxygen species and oxidative stress [35] (Fig. 1). HHcy also affects ion channels, inducing intracellular calcium influx associated with mitochondrial dysregulation, DNA damage, and cell death [91-93]. Studies on ALS have reported HHcy in patients plasma and cerebrospinal fluids [94, 95], discussed as a factor in the predisposition of motor neurons to the process of excitotoxicity and oxidative stress, due to interactions in glutamatergic receptors, which causes higher sensitivity in the release process of glutamate neurotransmitters $[94,96]$.

Moreover, the increased Hcy level in the bloodstream could contribute to muscle denervation and neurodegeneration, given that the concentration of this amino acid is ten times higher in the bloodstream of ALS patients than in their central nervous system [95]. This suggests that Hcy might act at neuromuscular junctions and skeletal muscles [35].

Of the main process arising from the MTHFR gene polymorphism liked to HHcy, oxidative stress presents itself as a mechanism implicated in many intracellular alterations in ALS neurodegeneration [97]. In the 
transsulfuration pathway, Hcy is converted to cystathionine and later to cysteine, the precursor molecule in protein and glutathione (GSH) synthesis. Glutathione is an essential antioxidant compound that acts against oxidative imbalance and cell damage by capturing reactive oxygen species (ROS) $[98,99]$. Intracellular folate deficiency due to MTHFR gene polymorphism compromises glutathione metabolism since SAM allosterically regulates GSH production $[100,101]$ (Fig. 1). In brain tissue, the conversion of cystathionine to cysteine does not occur, and the process of GSH synthesis is dependent on cysteine transporters [102]. In this way, studies report low levels of glutathione in brain tissue, causing greater susceptibility of neurons to oxidative stress and development of ALS [103, 104] (Fig. 1). On the other hand, folate deficiency and HHcy contribute to oxidative stress, once the Hcy interacts with cysteine transporters preventing GSH synthesis [105].

As previously mentioned, the MTHFR C677T polymorphism can also affect DNA synthesis via the thymidylate pathway by MTHFD and TMS enzymes [19]. In this pathway, the 5,10-MTHF is reduced and oxidized to 10-Formiltetrahydrofolate, which donates a methyl group for the conversion of deoxyuridine-5monophosphate (dUMP) to dTMP $[106,107]$ (Fig. 2). Although not well understood, deficiency in the MTHFR enzyme is known to result in the accumulation of the 10-Formiltetrahydrofolate molecule due to the non-conversion of 5,10-MTHFR to 5-MTHF, stimulating dTMP synthesis [108]. Thus, the synthesis of new thymidylate is an alternative for intracellular folate reactions in cases of MTHFR enzyme deficiency, possibly increasing the dTMP concentration in plasma.

The increased production of thymidylate contributes to oxidative stress, as its entire synthesis process is performed by oxidation-reduction reactions that depend on NADPH [20, 21]. NADPH is a major ROS generator that contributes to the development of neurodegenerative diseases, including ALS, due to the release of free radicals in the brain and the vulnerability of this tissue to oxidizing agents [109]. Increased plasma thymidine levels have been reported in neurogastrointestinal mitochondrial encephalomyopathy disease (MNGIE), discussed as a cause in mitochondrial DNA imbalance associated with symptoms such as mental regression, ophthalmoplegia, and fatal gastrointestinal complications [110]. Moreover, increased thymidylate was reported in carcinoma cells as an angiogenic factor associated with oxidative stress, stimulation of pro-inflammatory interleukin secretion, and vascular endothelial growth factor secretion (VEGF) [111].

In addition to analyzing the MTHFR C677T polymorphism as a possible risk factor for ALS, this study also identified associations between the genotypic profile and sociodemographic and clinical factors reported by the individuals in the case group. Interactions between genotype (T/T) and factors such as ethnicity in white $(p=0.005)$ and brown $(p=0.001)$ individuals, as well as physical activity $(p=0.006)$ were observed (Table 3). Other important variables, such as gender, alcohol consumption, smoking, ALS classification, neurological disease in the family, and previous pathologies showed no interactions with the genotypic profile presented in the case group.

The association of ethnicity with the MTHFR C677T polymorphism is consistent with the higher prevalence of this genetic variable in white people such as Hispanic, Italian, Californian, and others. 
Conversely, the lowest incidence was reported in Black people, including North America, Brazil, and subSaharan Africa [24]. Since studies suggest that genetic influences can explain the higher frequency in white populations [5], it is possible that the variation in the MTHFR gene is a factor, in agreement with the results presented in our study.

Physical activity is considered a risk factor for ALS due to the increase in energy expenditure associated with oxidative stress (discussed earlier in this study). Moreover, the relationship between physical activity and genetic contributions in ALS susceptibility has been discussed [61]. In this context, the results obtained in this study show an interaction between physical activity and MTHFR C677T polymorphism in disease susceptibility. This interaction perhaps results from the possibility that both of these risk factors contribute to oxidative stress.

ALS is a rapidly progressing disease and has a median survival time of three to five years. However, there are discrepant cases in which survival exceeds ten years, as was the case of the famous physicist Stephen Hawking $[112,113]$. The precise causes of these longer survival cases are still unknown; however, genetic and environmental factors are possible causes [114].

In this study, we performed a comparative analysis between the C677T MTHFR polymorphism and the death, which showed a statistical trend towards more significant ALS progression and early death in patients with the heterozygous (C/T) genotype compared to the wild genotype $(C / C)(p=0.06)(F i g .2)$. Until the data collection period, there were no cases of death with the genotype $(T / T)$. A study by Tsang et al. [115] reports that the heterozygous genotype (C/T) exhibited the most significant effect of MTHFR C677T polymorphism on decreasing blood folate, which surprisingly corroborates our data. This result suggests a higher pathogenic risk and earlier death in heterozygous $(C / T)$ than mutant homozygous $(T / T)$ genotypes.

\section{Conclusion}

There is ample evidence that folate deficiency and MTHFR C677T polymorphism are associated with the development of various disorders, including neurodegenerative diseases. This polymorphism is known to result in hypomethylation, HHcy, aberrant stimulation of nucleotide synthesis, oxidative stress, and cell death, which may be implicated in the pathogenesis and progression of ALS neurodegeneration.

We have found that the MTHFR C677T polymorphism is possibly implicated in the pathogenesis of ALS and is a risk factor for the development and progression of the disease. Furthermore, we found a risk interaction of the mutant genotype with sociodemographic and clinical factors, which increases susceptibility to the disease. Moreover, within the modifiable factors, alcohol consumption was a possible risk factor, independently of genotype.

Since ALS is a fast-progressing disease without a definitive diagnosis and effective treatment, the results of this study are highly relevant in the search for a possible biomarker for its diagnosis and prognosis. Such a biomarker could serve as a complementary tool in early diagnosis and improve the effectiveness 
of riluzole treatment. This study also highlights the possible relationship between folate cycle dysregulation to the pathogenesis of the disease; however, further studies are needed to elucidate how these factors contribute to ALS pathogenesis.

\section{Declarations}

\section{Acknowledgment}

The authors would like to thank the reference hospital for neuromuscular disease, Dr. Henrique Santilho Rehabilitation and Readaptation Center (CRER), and the Laboratory of Clinical Analysis and Health Education of the Federal University of Goiás (LACES-UFG) for providing samples to realize this study. We would like to thank all the participants in this study, especially ALS patients. We mourn all the deaths that occurred during the study and sympathize with the painful loss of the families.

\section{Author contributions}

Conceptualization: Rômulo Morais Azevedo, Angela Adamski da Silva Reis and Rodrigo da Silva Santos, Methodology and Validation: Rômulo Morais Azevedo, Kamilla de Faria Santos, Rayana Pereira Dantas de Oliveira, Júllia Costa Pereira, Dhiogo da Cruz Pereira Bento, Angela Adamski da Silva Reis and Rodrigo da Silva Santos, Formal analysis: Rômulo Morais Azevedo, Kamilla de Faria Santos, Rayana Pereira Dantas de Oliveira and Júllia Costa Pereira, Investigation: Rômulo Morais Azevedo, Kamilla de Faria Santos, Rayana Pereira Dantas de Oliveira, Júllia Costa Pereira, Dhiogo da Cruz Pereira Bento, Angela Adamski da Silva Reis and Rodrigo da Silva Santos, Resources: Rômulo Morais Azevedo, Angela Adamski da Silva Reis and Rodrigo da Silva Santos, Data curation: Rômulo Morais Azevedo, Kamilla de Faria Santos, Rayana Pereira Dantas de Oliveira, Júllia Costa Pereira, Angela Adamski da Silva Reis and Rodrigo da Silva Santos, Writing: Rômulo Morais Azevedo, Angela Adamski da Silva Reis and Rodrigo da Silva Santos, Writing-review and editing: Rômulo Morais Azevedo, Kamilla de Faria Santos, Júllia Costa Pereira, Angela Adamski da Silva Reis and Rodrigo da Silva Santos, Visualization: Rômulo Morais Azevedo, Kamilla de Faria Santos, Rayana Pereira Dantas de Oliveira, Júllia Costa Pereira, Angela Adamski da Silva Reis and Rodrigo da Silva Santos, Supervision and Project administration: Angela Adamski da Silva Reis and Rodrigo da Silva Santos, Funding acquisition: Angela Adamski da Silva Reis and Rodrigo da Silva Santos.

\section{Funding}

This work was supported by the Postgraduate Program in Assessment and Health Care from Faculty of Pharmacy, Federal University of Goiás (PPGAAS-FF-UFG), and personal resources from the research coordinators (Rodrigo da Silva Santos, Ph.D., and Angela Adamski da Silva Reis, Ph.D.).

\section{Compliance with ethical standards}

Conflict of interest: The authors declare that they have no conflict of interest or no financial conflict of interest to disclose. 
Ethical approval: All procedures performed in studies involving human participants were in accordance with the ethical standards of the institutional and/or national research committee and with the 1964 Helsinki declaration and its later amendments or comparable ethical standards. This study was approved by the Ethical Committee of Federal University of Goiás (protocol: CAAE 79593117.7.0000.5083).

Informed consent: Patients signed their written informed consent, which was approved by the Ethical Committee of Federal University of Goiás (protocol: CAAE 79593117.7.0000.5083). The informed consent was obtained from the pacient(s) and/or legally autorized representative (LAR) signed informed consent regarding publishing their data.

\section{References}

1. Al-Chalabi, A., Hardiman, O., Kiernan, M.C., Chiò, A., Rix-Brooks, B., van den Berg, L.H., (2016) Amyotrophic lateral sclerosis: moving towards a new classification system. Lancet Neurol. 15, 1182-1194. https://doi.org/10.1016/S1474-4422(16)30199-5

2. Oskarsson, B., Gendron, T.F., Staff, N.P., 2018. Amyotrophic Lateral Sclerosis: An Update for (2018) Mayo Clin. Proc. 93, 1617-1628. https://doi.org/10.1016/j.mayocp.2018.04.007

3. Grollemund, V., Pradat, P.-F., Querin, G., Delbot, F., Le Chat, G., Pradat-Peyre, J.-F., Bede, P., (2019) Machine Learning in Amyotrophic Lateral Sclerosis: Achievements, Pitfalls, and Future Directions. Front. Neurosci. 13, 1-28. https://doi.org/10.3389/fnins.2019.00135

4. Marin, B., Boumédiene, F., Logroscino, G., Couratier, P., Babron, M.-C., Leutenegger, A.L., Copetti, M., Preux, P.-M., Beghi, E., (2017) Variation in worldwide incidence of amyotrophic lateral sclerosis: a meta-analysis. Int. J. Epidemiol. 46, 57-74. https://doi.org/10.1093/ije/dyw061

5. Wei, Q., Chen, X., Chen, Y., Ou, R., Cao, B., Hou, Y., Zhang, L., Shang, H.F., (2019) Unique characteristics of the genetics epidemiology of amyotrophic lateral sclerosis in China. Sci. China Life Sci. 62, 517518. https://doi.org/10.1007/s11427-018-9453-x

6. Hardiman, O., Al-Chalabi, A., Chio, A., Corr, E.M., Logroscino, G., Robberecht, W., Shaw, P.J., Simmons, Z., van den Berg, L.H., (2017) Amyotrophic lateral sclerosis. Nat. Rev. Dis. Prim. 3, 17071. https://doi.org/10.1038/nrdp.2017.71

7. Longinetti, E., Fang, F., (2019) Epidemiology of amyotrophic lateral sclerosis: an update of recent literature. Curr. Opin. Neurol. 32, 1-6. https://doi.org/10.1097/WC0.0000000000000730

8. Bertazzi, R.N., Martins, F.R., Saade, S.Z.Z., Guedes, V.R., (2017) Esclerose lateral amiotrófica/Amyotrophic lateral sclerosis. Rev. Patol. do Tocantins 4, 54. https://doi.org/10.20873/uft.2446-6492.2017v4n3p54

9. Chia, R., Chiò, A., Traynor, B.J., (2018) Novel genes associated with amyotrophic lateral sclerosis: diagnostic and clinical implications. Lancet Neurol. 17, 94-102. https://doi.org/10.1016/S14744422(17)30401-5

10. Souza, P.V.S. de, Pinto, W.B.V. de R., Chieia, M.A.T., Oliveira, A.S.B., (2015) Clinical and genetic basis of familial amyotrophic lateral sclerosis. Arq. Neuropsiquiatr. 73, 1026-1037. 
https://doi.org/10.1590/0004-282X20150161

11. Van den Bos, M.A.J., Geevasinga, N., Higashihara, M., Menon, P., Vucic, S., (2019) Pathophysiology and diagnosis of ALS: Insights from advances in neurophysiological techniques. Int. J. Mol. Sci. https://doi.org/10.3390/ijms20112818

12. Lacomis, D., Gooch, C., (2019) Upper motor neuron assessment and early diagnosis in ALS. Neurology 92, 255-256. https://doi.org/10.1212/WNL.0000000000006867

13. Mitchell, J.D., Callagher, P., Gardham, J., Mitchell, C., Dixon, M., Addison-Jones, R., Bennett, W., O’Brien, M.R., (2010) Timelines in the diagnostic evaluation of people with suspected amyotrophic lateral sclerosis (ALS)/motor neuron disease (MND) - a 20-year review: Can we do better? Amyotroph. Lateral Scler. 11, 537-541. https://doi.org/10.3109/17482968.2010.495158

14. Zhou, L., Tian, Z., Yao, M., Chen, X., Song, Y., Ye, J., Yi, N., Cui, X., Wang, Y., (2019) Riluzole promotes neurological function recovery and inhibits damage extension in rats following spinal cord injury: a meta-analysis and systematic review. J. Neurochem. 150, 6-27. https://doi.org/10.1111/jnc.14686

15. Zoing, M.C., Burke, D., Pamphlett, R., Kiernan, M.C., (2006) Riluzole therapy for motor neurone disease: An early Australian experience (1996-2002). J. Clin. Neurosci. 13, 78-83. https://doi.org/10.1016/j.jocn.2004.04.011

16. Liew, S.-C., (2016) Folic acid and diseases - supplement it or not? Rev. Assoc. Med. Bras. 62, 90-100. https://doi.org/10.1590/1806-9282.62.01.90

17. Zur-Wyrozumska, K., Pera, J., Dziubek, A., Sado, M., Golenia, A., Słowik, A., Dziedzic, T., (2017) Association between C677T polymorphism of MTHFR gene and risk of amyotrophic lateral sclerosis: Polish population study and a meta-analysis. Neurol. Neurochir. Pol. 51, 135-139. https://doi.org/10.1016/j.pjnns.2017.01.008

18. Wan, L., Li, Y., Zhang, Z., Sun, Z., He, Y., Li, R., (2018) Methylenetetrahydrofolate reductase and psychiatric diseases. Transl. Psychiatry 8, 242. https://doi.org/10.1038/s41398-018-0276-6

19. Stover, P.J., (2009) One-Carbon Metabolism-Genome Interactions in Folate-Associated Pathologies. J. Nutr. 139, 2402-2405. https://doi.org/10.3945/jn.109.113670

20. Neagos, D., Cretu, R., Tutulan-Cunita, A., Stoian, V., Bohiltea, L.C., (2010) Methylenetetrahydrofolate dehydrogenase (MTHFD) enzyme polymorphism as a maternal risk factor for trisomy 21: a clinical study. J. Med. Life 3, 454-457.

21. Field, M.S., Kamynina, E., Watkins, D., Rosenblatt, D.S., Stover, P.J., (2015) Human mutations in methylenetetrahydrofolate dehydrogenase 1 impair nuclear de novo thymidylate biosynthesis. Proc. Natl. Acad. Sci. 112, 400-405. https://doi.org/10.1073/pnas.1414555112

22. Froese, D.S., Fowler, B., Baumgartner, M.R., (2019) Vitamin B12, folate, and the methionine remethylation cycle-biochemistry, pathways, and regulation. J. Inherit. Metab. Dis. 42, 673-685. https://doi.org/10.1002/jimd.12009

23. Hiraoka, M., Kagawa, Y., (2017) Genetic polymorphisms and folate status. Congenit. Anom. (Kyoto). 57, 142-149. https://doi.org/10.1111/cga.12232 
24. Liew, S.-C., Gupta, E. Das., (2015) Methylenetetrahydrofolate reductase (MTHFR) C677T polymorphism: Epidemiology, metabolism and the associated diseases. Eur. J. Med. Genet. 58, 1-10. https://doi.org/10.1016/j.ejmg.2014.10.004

25. Husemoen, L.L.N., Skaaby, T., Jørgensen, T., Thuesen, B.H., Fenger, M., Grarup, N., Sandholt, C.H., Hansen, T., Pedersen, O., Linneberg, A., (2014) MTHFR C677T genotype and cardiovascular risk in a general population without mandatory folic acid fortification. Eur. J. Nutr. 53, 1549-1559. https://doi.org/10.1007/s00394-014-0659-2

26. Li, A., Shi, Y., Xu, L., Zhang, Y., Zhao, H., Li, Q., Zhao, X., Cao, X., Zheng, H., He, Y., (2017) A possible synergistic effect of MTHFR C677T polymorphism on homocysteine level variations increased risk for ischemic stroke. Medicine (Baltimore). 96, 1-5. https://doi.org/10.1097/MD.0000000000009300

27. Galbiatti, A.L.S., Ruiz, M.T., Maniglia, J.V., Raposo, L.S., Pavarino-Bertelli, É.C., Goloni-Bertollo, E.M., (2012) Head and neck cancer: genetic polymorphisms and folate metabolism. Braz. J. Otorhinolaryngol. 78, 132-139. https://doi.org/10.1590/S1808-86942012000100021

28. Izmirli, M., (2013) A literature review of MTHFR (C677T and A1298C polymorphisms) and cancer risk. Mol. Biol. Rep. 40, 625-637. https://doi.org/10.1007/s11033-012-2101-2

29. Kheradmand, M., Maghbooli, Z., Salemi, S., Sanjari, M., (2017) Associations of MTHFR C677T polymorphism with insulin resistance, results of NURSE Study (Nursing Unacquainted Related Stress Etiologies). J. Diabetes Metab. Disord. 16, 22. https://doi.org/10.1186/s40200-017-0303-9

30. Qian, X., Lu, Z., Tan, M., Liu, H., Lu, D., (2007) A meta-analysis of association between C677T polymorphism in the methylenetetrahydrofolate reductase gene and hypertension. Eur. J. Hum. Genet. 15, 1239-1245. https://doi.org/10.1038/sj.ejhg.5201914

31. Rai, V., (2018) Strong Association of C677T Polymorphism of Methylenetetrahydrofolate Reductase Gene With Nosyndromic Cleft Lip/Palate (nsCL/P). Indian J. Clin. Biochem. 33, 5-15. https://doi.org/10.1007/s12291-017-0673-2

32. Coşar, A., İp̧̧ioğlu, O.M., Özcan, Ö., Gültepe, M., (2014) Folate and homocysteine metabolisms and their roles in the biochemical basis of neuropsychiatry. Turkish J. Med. Sci. 44, 1-9. https://doi.org/10.3906/sag-1211-39

33. Zheng, Z., Wang, J., Yi, L., Yu, H., Kong, L., Cui, W., Chen, H., Wang, C., (2014) Correlation between Behavioural and Psychological Symptoms of Alzheimer Type Dementia and Plasma Homocysteine Concentration. Biomed Res. Int. 2014, 1-6. https://doi.org/10.1155/2014/383494

34. Zoccolella, S., Bendotti, C., Beghi, E., Logroscino, G., (2010) Homocysteine levels and amyotrophic lateral sclerosis: A possible link. Amyotroph. Lateral Scler. 11, 140-147. https://doi.org/10.3109/17482960902919360

35. Bukharaeva, E., Shakirzyanova, A., Khuzakhmetova, V., Sitdikova, G., Giniatullin, R., (2015) Homocysteine aggravates ROS-induced depression of transmitter release from motor nerve terminals: potential mechanism of peripheral impairment in motor neuron diseases associated with hyperhomocysteinemia. Front. Cell. Neurosci. 9, 1-8. https://doi.org/10.3389/fncel.2015.00391 
36. Little, J., Higgins, J.P.., loannidis, J.P.., Moher, D., Gagnon, F., von Elm, E., Khoury, M.J., Cohen, B., Davey-Smith, G., Grimshaw, J., Scheet, P., Gwinn, M., Williamson, R.E., Zou, G.Y., Hutchings, K., Johnson, C.Y., Tait, V., Wiens, M., Golding, J., van Duijn, C., McLaughlin, J., Paterson, A., Wells, G., Fortier, I., Freedman, M., Zecevic, M., King, R., Infante-Rivard, C., Stewart, A., Birkett, N., (2009) STrengthening the REporting of Genetic Association Studies (STREGA) - An Extension of the STROBE Statement. PLoS Med. 6, 0151-0153. https://doi.org/10.1371/journal.pmed.1000022

37. Keku, T., Millikan, R., Worley, K., Winkel, S., Eaton, A., Biscocho, L., Martin, C., Sandler, R., (2002) 5,10Methylenetetrahydrofolate reductase codon 677 and 1298 polymorphisms and colon cancer in African Americans and whites. Cancer Epidemiol. Biomarkers Prev. 11, 1611-21.

38. Ingre, C., Roos, P.M., Piehl, F., Kamel, F., Fang, F., (2015) Risk factors for amyotrophic lateral sclerosis. Clin. Epidemiol. 7, 181-193. https://doi.org/10.2147/CLEP.S37505

39. Grad, L.I., Rouleau, G.A., Ravits, J., Cashman, N.R., (2017) Clinical Spectrum of Amyotrophic Lateral Sclerosis (ALS). Cold Spring Harb. Perspect. Med. 7, a024117. https://doi.org/10.1101/cshperspect.a024117

40. Ragagnin, A.M.G., Shadfar, S., Vidal, M., Jamali, M.S., Atkin, J.D., (2019) Motor Neuron Susceptibility in ALS/FTD. Front. Neurosci. 13, 1-37. https://doi.org/10.3389/fnins.2019.00532

41. McCombe, P.A., Henderson, R.D., (2010) Effects of gender in amyotrophic lateral sclerosis. Gend. Med. 7, 557-570. https://doi.org/10.1016/j.genm.2010.11.010

42. Rooney, J.P.K., Visser, A.E., D’Ovidio, F., Vermeulen, R., Beghi, E., Chio, A., Veldink, J.H., Logroscino, G., van den Berg, L.H., Hardiman, O., (2017) A case-control study of hormonal exposures as etiologic factors for ALS in women. Neurology 89, 1283-1290.

https://doi.org/10.1212/WNL.0000000000004390

43. Slowik, A., Beyer, C., (2015) Inflammasomes are neuroprotective targets for sex steroids. J. Steroid Biochem. Mol. Biol. 153, 135-143. https://doi.org/10.1016/j.jsbmb.2015.02.013

44. Lejri, I., Grimm, A., Eckert, A., (2018) Mitochondria, Estrogen and Female Brain Aging. Front. Aging Neurosci. 10, 1-12. https://doi.org/10.3389/fnagi.2018.00124

45. Slowik, A., Lammerding, L., Hoffmann, S., Beyer, C., (2018) Brain inflammasomes in stroke and depressive disorders: Regulation by oestrogen. J. Neuroendocrinol. 30, e12482. https://doi.org/10.1111/jne.12482

46. Ashley F. Curtis, Mario Masellis, Ging-Yuek Robin Hsiung, Rahim Moineddin, Kathy Zhang, Bonnie Au, Geneva Millett, lan Mackenzie, Ekaterina Rogaeva, Mary C. Tierney, (2017) Sex differences in the prevalence of genetic mutations in FTD and ALS A meta-analysis. Neurology 89, 1633-1642.

47. Roberts, A.L., Johnson, N.J., Chen, J.T., Cudkowicz, M.E., Weisskopf, M.G., (2016) Race/ethnicity, socioeconomic status, and ALS mortality in the United States. Neurology 87, 2300-2308. https://doi.org/10.1212/WNL.0000000000003298

48. Rechtman, L., Jordan, H., Wagner, L., Horton, D.K., Kaye, W., (2015) Racial and ethnic differences among amyotrophic lateral sclerosis cases in the United States. Amyotroph. Lateral Scler. Front. Degener. 16, 65-71. https://doi.org/10.3109/21678421.2014.971813 
49. Wang, M.-D., Little, J., Gomes, J., Cashman, N.R., Krewski, D., (2017) Identification of risk factors associated with onset and progression of amyotrophic lateral sclerosis using systematic review and meta-analysis. Neurotoxicology 61, 101-130. https://doi.org/10.1016/j.neuro.2016.06.015

50. D’Ovidio, F., Rooney, J.P.K., Visser, A.E., Manera, U., Beghi, E., Logroscino, G., Vermeulen, R.C.H., Veldink, J.H., van den Berg, L.H., Hardiman, O., Chiò, A., (2019) Association between alcohol exposure and the risk of amyotrophic lateral sclerosis in the Euro-MOTOR study. J. Neurol. Neurosurg. Psychiatry 90, 11-19. https://doi.org/10.1136/jnnp-2018-318559

51. Holmes, A., Spanagel, R., Krystal, J.H., (2013) Glutamatergic targets for new alcohol medications. Psychopharmacology (Berl). 229, 539-554. https://doi.org/10.1007/s00213-013-3226-2

52. Rossetti, I., Zambusi, L., Maccioni, P., Sau, R., Provini, L., Castelli, M.P., Gonciarz, K., Colombo, G., Morara, S., (2019) Predisposition to Alcohol Drinking and Alcohol Consumption Alter Expression of Calcitonin Gene-Related Peptide, Neuropeptide Y, and Microglia in Bed Nucleus of Stria Terminalis in a Subnucleus-Specific Manner. Front. Cell. Neurosci. 13, 1-14.

https://doi.org/10.3389/fncel.2019.00158

53. Alonso, A., Logroscino, G., Jick, S.S., Hernán, M.A., (2010) Association of smoking with amyotrophic lateral sclerosis risk and survival in men and women: a prospective study. BMC Neurol. 10, 6. https://doi.org/10.1186/1471-2377-10-6

54. Alkam, T., Nabeshima, T., (2019) Molecular mechanisms for nicotine intoxication. Neurochem. Int. 125, 117-126. https://doi.org/10.1016/j.neuint.2019.02.006

55. Alrouji, M., Manouchehrinia, A., Gran, B., Constantinescu, C.S., (2019) Effects of cigarette smoke on immunity, neuroinflammation and multiple sclerosis. J. Neuroimmunol. 329, 24-34. https://doi.org/10.1016/j.jneuroim.2018.10.004

56. Chen, A., Montes, J., Mitsumoto, H., (2008) The Role of Exercise in Amyotrophic Lateral Sclerosis. Phys. Med. Rehabil. Clin. N. Am. 19, 545-557. https://doi.org/10.1016/j.pmr.2008.02.003

57. Beghi, E., (2013) Are professional soccer players at higher risk for ALS. Amyotroph. Lateral Sclerosis. Front. Degener. 14, 501-506. https://doi.org/10.3109/21678421.2013.809764

58. Vandoorne, T., De Bock, K., Van Den Bosch, L., (2018) Energy metabolism in ALS: an underappreciated opportunity?. Acta Neuropathol. 135, 489-509. https://doi.org/10.1007/s00401018-1835-x

59. Kirk, S.E., Tracey, T.J., Steyn, F.J., Ngo, S.T., (2019) Biomarkers of Metabolism in Amyotrophic Lateral Sclerosis. Front. Neurol. 10, 191. https://doi.org/10.3389/fneur.2019.00191

60. Svensson, M., Lexell, J., Deierborg, T., (2015) Effects of Physical Exercise on Neuroinflammation, Neuroplasticity, Neurodegeneration, and Behavior. Neurorehabil. Neural Repair 29, 577-589. https://doi.org/10.1177/1545968314562108

61. Huisman, M.H.B., Seelen, M., De Jong, S.W., Dorresteijn, K.R.I.S., Van Doormaal, P.T.C., Van Der Kooi, A.J., De Visser, M., Schelhaas, H.J., Van Den Berg, L.H., Veldink, J.H., (2013) Lifetime physical activity and the risk of amyotrophic lateral sclerosis. J. Neurol. Neurosurg. Psychiatry 84, 976-981. https://doi.org/10.1136/jnnp-2012-304724 
62. Wang, M.-D., Gomes, J., Cashman, N.R., Little, J., Krewski, D., (2014) A Meta-Analysis of Observational Studies of the Association Between Chronic Occupational Exposure to Lead and Amyotrophic Lateral Sclerosis. J. Occup. Environ. Med. 56, 1235-1242. https://doi.org/10.1097/JOM.0000000000000323

63. Bozzoni, V., (2016) Amyotrophic lateral sclerosis and environmental factors. Funct. Neurol. 31, 7-19. https://doi.org/10.11138/FNeur/2016.31.1.007

64. Lacorte, E., Ferrigno, L., Leoncini, E., Corbo, M., Boccia, S., Vanacore, N., (2016) Physical activity, and physical activity related to sports, leisure and occupational activity as risk factors for ALS: A systematic review. Neurosci. Biobehav. Rev. 66, 61-79. https://doi.org/10.1016/j.neubiorev.2016.04.007

65. Peters, T.L., Kamel, F., Lundholm, C., Feychting, M., Weibull, C.E., Sandler, D.P., Wiebert, P., Sparén, P., Ye, W., Fang, F., (2017) Occupational exposures and the risk of amyotrophic lateral sclerosis. Occup. Environ. Med. 74, 87-92. https://doi.org/10.1136/oemed-2016-103700

66. Fallis, B.A., Hardiman, O., (2009) Aggregation of neurodegenerative disease in ALS kindreds. Amyotroph. Lateral Scler. 10, 95-98. https://doi.org/10.1080/17482960802209664

67. Longinetti, E., Mariosa, D., Larsson, H., Ye, W., Ingre, C., Almqvist, C., Lichtenstein, P., Piehl, F., Fang, F., (2017) Neurodegenerative and psychiatric diseases among families with amyotrophic lateral sclerosis. Neurology 89, 578-585. https://doi.org/10.1212/WNL.0000000000004179

68. Byrne, S., Heverin, M., Elamin, M., Bede, P., Lynch, C., Kenna, K., Maclaughlin, R., Walsh, C., Al Chalabi, A., Hardiman, O., (2013) Aggregation of neurologic and neuropsychiatric disease in amyotrophic lateral sclerosis kindreds: A population-based case-control cohort study of familial and sporadic amyotrophic lateral sclerosis. Ann. Neurol. 74, 699-708. https://doi.org/10.1002/ana.23969

69. Huisman, M.H.B., de Jong, S.W., Verwijs, M.C., Schelhaas, H.J., van der Kooi, A.J., de Visser, M., Veldink, J.H., van den Berg, L.H., (2011) Family history of neurodegenerative and vascular diseases in ALS: A population-based study. Neurology 77, 1363-1369.

https://doi.org/10.1212/WNL.0b013e318231530b

70. Jaiswal, M.K., (2019) Riluzole and edaravone: A tale of two amyotrophic lateral sclerosis drugs. Med. Res. Rev. 39, 733-748. https://doi.org/10.1002/med.21528

71. Shefner, J.M., Cudkowicz, M.E., Hardiman, O., Cockroft, B.M., Lee, J.H., Malik, F.I, Meng, L., Rudnicki, S.A., Wolff, A.A., Andrews, J.A., (2019) A phase III trial of tirasemtiv as a potential treatment for amyotrophic lateral sclerosis. Amyotroph. Lateral Scler. Front. Degener. 0, 1-11. https://doi.org/10.1080/21678421.2019.1612922

72. Kühnlein, P., Jung, H., Farkas, M., Keskitalo, S., Ineichen, B., Jelcic, I., Petersen, J., Semmler, A., Weller, M., Ludolph, A.C., Linnebank, M., (2011) The thermolabile variant of 5,10-methylenetetrahydrofolate reductase is a possible risk factor for amyotrophic lateral sclerosis. Amyotroph. Lateral Scler. 12, 136-139. https://doi.org/10.3109/17482968.2010.536985

73. Sazci, A., Ozel, M.D., Emel, E., Idrisoglu, H.A., (2012) Gender-Specific Association of Methylenetetrahydrofolate Reductase Gene Polymorphisms with Sporadic Amyotrophic Lateral 
Sclerosis. Genet. Test. Mol. Biomarkers 16, 716-721. https://doi.org/10.1089/gtmb.2011.0313

74. Lintas, C., (2019) Linking genetics to epigenetics: The role of folate and folate-related pathways in neurodevelopmental disorders. Clin. Genet. 95, 241-252. https://doi.org/10.1111/cge.13421

75. Reynolds, E., (2006) Vitamin B12, folic acid, and the nervous system. Lancet Neurol. 5, 949-960. https://doi.org/10.1016/S1474-4422(06)70598-1

76. Craenen, K., Verslegers, M., Baatout, S., Abderrafi Benotmane, M., (2019) An appraisal of folates as key factors in cognition and ageing-related diseases. Crit. Rev. Food Sci. Nutr. 0, 1-18. https://doi.org/10.1080/10408398.2018.1549017

77. Schwahn, B., Rozen, R., (2001) Polymorphisms in the methylenetetrahydrofolate reductase gene: Clinical consequences. Am. J. Pharmacogenomics. 1, 189-201. https://doi.org/10.2165/00129785200101030-00004

78. Gaughan, D.J., Barbaux, S., Kluijtmans, L.A.J., Whitehead, A.S., (2000) The human and mouse methylenetetrahydrofolate reductase (MTHFR) genes: genomic organization, mRNA structure and linkage to the CLCN6 gene. Gene 257, 279-289. https://doi.org/10.1016/S0378-1119(00)00392-9

79. Rai V. (2016) Folate Pathway Gene Methylenetetrahydrofolate Reductase C677T Polymorphism and Alzheimer Disease Risk in Asian Population. Indian J Clin Biochem. 31(3): 245-52. https://doi.org/10.1007/s12291-015-0512-2

80. Chang, Yu-Tzu, Hsu, S.-W., Tsai, S.-J., Chang, Ya-Ting, Huang, C.-W., Liu, M.-E., Chen, N.-C., Chang, W.N., Hsu, J.-L., Lee, C.-C., Chang, C.-C., (2017) Genetic effect of MTHFR C677T polymorphism on the structural covariance network and white-matter integrity in Alzheimer's disease. Hum. Brain Mapp. 38, 3039-3051. https://doi.org/10.1002/hbm.23572

81. Zhu, Y., Zhu, R.-X., He, Z.-Y., Liu, X., Liu, H.-N., (2015) Association of MTHFR C677T with total homocysteine plasma levels and susceptibility to Parkinson's disease: a meta-analysis. Neurol. Sci. 36, 945-951. https://doi.org/10.1007/s10072-014-2052-6

82. Liu, L., Zhang, L., Guo, L., Yu, Q., Li, H., Teng, J., Xie, A., (2018) MTHFR C677T and A1298C polymorphisms may contribute to the risk of Parkinson's disease: A meta-analysis of 19 studies. Neurosci. Lett. 662, 339-345. https://doi.org/10.1016/j.neulet.2017.10.060

83. Warzyszynska, J.E., Kim, Y.-I.J., (2014) Folate in Human Health and Disease, in: ELS. John Wiley \& Sons, Ltd, Chichester, UK, pp. 193-194. https://doi.org/10.1002/9780470015902.a0002268.pub2

84. Mattson, M.P., Shea, T.B., (2003) Folate and homocysteine metabolism in neural plasticity and neurodegenerative disorders. Trends Neurosci. 26, 137-146. https://doi.org/10.1016/S01662236(03)00032-8

85. Stifani, N., (2014) Motor neurons and the generation of spinal motor neuron diversity. Front. Cell. Neurosci. https://doi.org/10.3389/fncel.2014.00293

86. Vermillion, K.L., Lidberg, K.A., Gammill, L.S., (2014) Cytoplasmic protein methylation is essential for neural crest migration. J. Cell Biol. 204, 95-109. https://doi.org/10.1083/jcb.201306071

87. Surtees, R., Leonard, J., Austin, S., (1991) Association of demyelination with deficiency of cerebrospinal-fluid S-adenosylmethionine in inborn errors of methyl-transfer pathway. Lancet 338, 
1550-1554. https://doi.org/10.1016/0140-6736(91)92373-A

88. Jadavji, N.M., Wieske, F., Dirnagl, U., Winter, C., (2015) Methylenetetrahydrofolate reductase deficiency alters levels of glutamate and $y$-aminobutyric acid in brain tissue. Mol. Genet. Metab. Reports 3, 1-4. https://doi.org/10.1016/j.ymgmr.2015.02.001

89. Bakulin, I.S., Chervyakov, A. V., Suponeva, N.A., Zakharova, M.N., Piradov, M.A., (2016) Motor Cortex Hyperexcitability, Neuroplasticity, and Degeneration in Amyotrophic Lateral Sclerosis, in: Update on Amyotrophic Lateral Sclerosis. InTech, p. 13. https://doi.org/10.5772/63310

90. Vermeiren, Y., Janssens, J., Van Dam, D., De Deyn, P.P., (2018) Serotonergic Dysfunction in Amyotrophic Lateral Sclerosis and Parkinson's Disease: Similar Mechanisms, Dissimilar Outcomes. Front. Neurosci. 12, 1-9. https://doi.org/10.3389/fnins.2018.00185

91. Lewinski, F. von, Keller, B.U., (2005) Ca2+, mitochondria and selective motoneuron vulnerability: implications for ALS. Trends Neurosci. 28, 494-500. https://doi.org/10.1016/j.tins.2005.07.001

92. Coppedè, F., Migliore, L., (2015) DNA damage in neurodegenerative diseases. Mutat. Res. Mol. Mech. Mutagen. 776, 84-97. https://doi.org/10.1016/j.mrfmmm.2014.11.010

93. Leal, S.S., Gomes, C.M., (2015) Calcium dysregulation links ALS defective proteins and motor neuron selective vulnerability. Front. Cell. Neurosci. 9, 1-6. https://doi.org/10.3389/fncel.2015.00225

94. Zoccolella, S., Simone, I.L., Lamberti, P., Samarelli, V., Tortelli, R., Serlenga, L., Logroscino, G., (2008) Elevated plasma homocysteine levels in patients with amyotrophic lateral sclerosis. Neurology 70 , 222-225. https://doi.org/10.1212/01.wnl.0000297193.53986.6f

95. Valentino, F., Bivona, G., Butera, D., Paladino, P., Fazzari, M., Piccoli, T., Ciaccio, M., La Bella, V., (2010) Elevated cerebrospinal fluid and plasma homocysteine levels in ALS. Eur. J. Neurol. 17, 84-89. https://doi.org/10.1111/j.1468-1331.2009.02752.x

96. Bhatia, P., Singh, N., (2015) Homocysteine excess: delineating the possible mechanism of neurotoxicity and depression. Fundam. Clin. Pharmacol. 29, 522-528. https://doi.org/10.1111/fcp.12145

97. Bozzo, F., Mirra, A., Carrì, M.T., (2017) Oxidative stress and mitochondrial damage in the pathogenesis of ALS: New perspectives. Neurosci. Lett. 636, 3-8. https://doi.org/10.1016/j.neulet.2016.04.065

98. Nazki, F.H., Sameer, A.S., Ganaie, B.A., (2014) Folate: Metabolism, genes, polymorphisms and the associated diseases. Gene 533, 11-20. https://doi.org/10.1016/j.gene.2013.09.063

99. Chen, Y., Han, M., Matsumoto, A., Wang, Y., Thompson, D.C., Vasiliou, V., (2018) Glutathione and Transsulfuration in Alcohol-Associated Tissue Injury and Carcinogenesis, in: Advances in Experimental Medicine and Biology. pp. 37-53. https://doi.org/10.1007/978-3-319-98788-03

100. Shan, X., (2001) Mutations in the regulatory domain of cystathionine beta-synthase can functionally suppress patient-derived mutations in cis. Hum. Mol. Genet. 10, 635-643. https://doi.org/10.1093/hmg/10.6.635

101. García-Giménez, J.L., Pallardó, F. V., (2014) Maintenance of glutathione levels and its importance in epigenetic regulation. Front. Pharmacol. 5, 1504-1509. https://doi.org/10.3389/fphar.2014.00088 
102. Finkelstein, J.D., (1998) The metabolism of homocysteine: pathways and regulation. Eur. J. Pediatr. 157, S40-S44. https://doi.org/10.1007/PL00014300

103. Vargas, M.R., Johnson, D.A., Johnson, J.A., (2011) Decreased glutathione accelerates neurological deficit and mitochondrial pathology in familial ALS-linked hSOD1G93A mice model. Neurobiol. Dis. 43, 543-551. https://doi.org/10.1016/j.nbd.2011.04.025

104. Weiduschat, N., Mao, X., Hupf, J., Armstrong, N., Kang, G., Lange, D.J., Mitsumoto, H., Shungu, D.C., (2014) Motor cortex glutathione deficit in ALS measured in vivo with the J-editing technique. Neurosci. Lett. 570, 102-107. https://doi.org/10.1016/j.neulet.2014.04.020

105. Veeranki, S., Tyagi, S., (2013) Defective Homocysteine Metabolism: Potential Implications for Skeletal Muscle Malfunction. Int. J. Mol. Sci. 14, 15074-15091. https://doi.org/10.3390/ijms140715074

106. Skibola, C.F., (2002) Polymorphisms in the thymidylate synthase and serine hydroxymethyltransferase genes and risk of adult acute lymphocytic leukemia. Blood. 99, 37863791. https://doi.org/10.1182/blood.V99.10.3786

107. Hagner, N., Joerger, M., (2010) Cancer chemotherapy: targeting folic acid synthesis. Cancer Manag. Res. 2, 293-301.

108. Quinlivan, E.P., Davis, S.R., Shelnutt, K.P., Henderson, G.N., Ghandour, H., Shane, B., Selhub, J., Bailey, L.B., Stacpoole, P.W., Gregory, J.F., (2005) Methylenetetrahydrofolate Reductase 677C $\rightarrow$ T Polymorphism and Folate Status Affect One-Carbon Incorporation into Human DNA Deoxynucleosides. J. Nutr. 135, 389-396. https://doi.org/10.1093/jn/135.3.389

109. Ma, M.W., Wang, J., Zhang, Q., Wang, R., Dhandapani, K.M., Vadlamudi, R.K., Brann, D.W., (2017) NADPH oxidase in brain injury and neurodegenerative disorders. Mol. Neurodegener. 12, 7. https://doi.org/10.1186/s13024-017-0150-7

110. Yadak, R., Sillevis Smitt, P., van Gisbergen, M.W., van Til, N.P., de Coo, I.F.M., (2017) Mitochondrial Neurogastrointestinal Encephalomyopathy Caused by Thymidine Phosphorylase Enzyme Deficiency: From Pathogenesis to Emerging Therapeutic Options. Front. Cell. Neurosci. 11, 1-14. https://doi.org/10.3389/fncel.2017.00031

111. Brown, N.S., Jones, A., Fujiyama, C., Harris, A.L., Bicknell, R., (2000) Thymidine phosphorylase induces carcinoma cell oxidative stress and promotes secretion of angiogenic factors. Cancer Res. $60,6298-6302$.

112. Preskill, J., (2018) Stephen Hawking (1942-2018). Science. 360, 156-156. https://doi.org/10.1126/science.aat6775

113. Foster, L.A., Salajegheh, M.K., (2019) Motor Neuron Disease: Pathophysiology, Diagnosis, and Management. Am. J. Med. 132, 32-37. https://doi.org/10.1016/j.amjmed.2018.07.012

114. Brown, R.H., Al-Chalabi, A., (2017) Amyotrophic Lateral Sclerosis. N. Engl. J. Med. 377, 162-172. https://doi.org/10.1056/NEJMra1603471

115. Tsang, B.L., Devine, O.J., Cordero, A.M., Marchetta, C.M., Mulinare, J., Mersereau, P., Guo, J., Qi, Y.P., Berry, R.J., Rosenthal, J., Crider, K.S., Hamner, H.C., (2015) Assessing the association between the 
methylenetetrahydrofolate reductase (MTHFR) 677C/T polymorphism and blood folate concentrations: a systematic review and meta-analysis of trials and observational studies. Am. J. Clin. Nutr. 101, 1286-1294. https://doi.org/10.3945/ajcn.114.099994

\section{Figures}

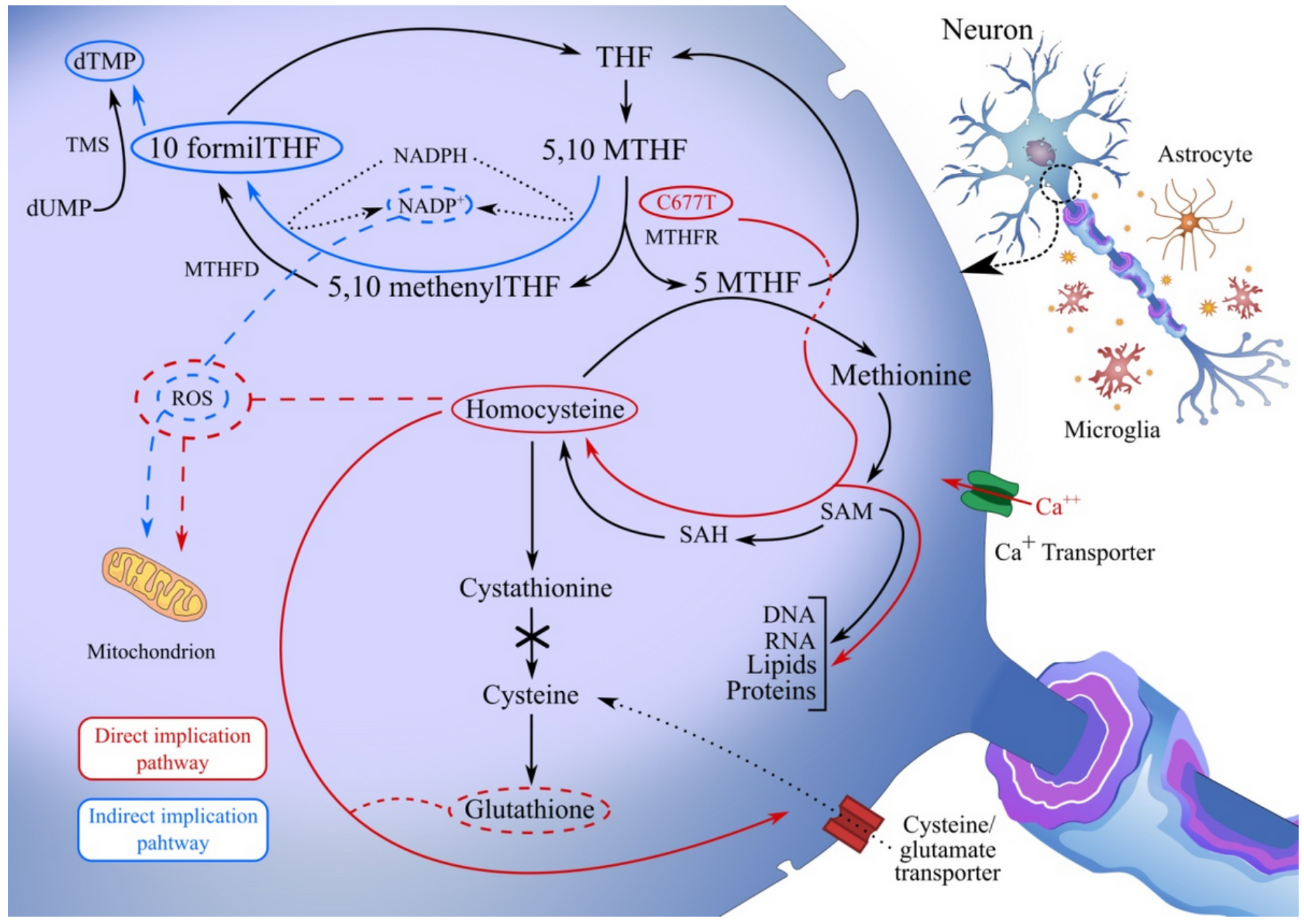

Figure 1

Hypothetical Model: MTHFR C677T polymorphism and possible folate cycle implication pathways. 


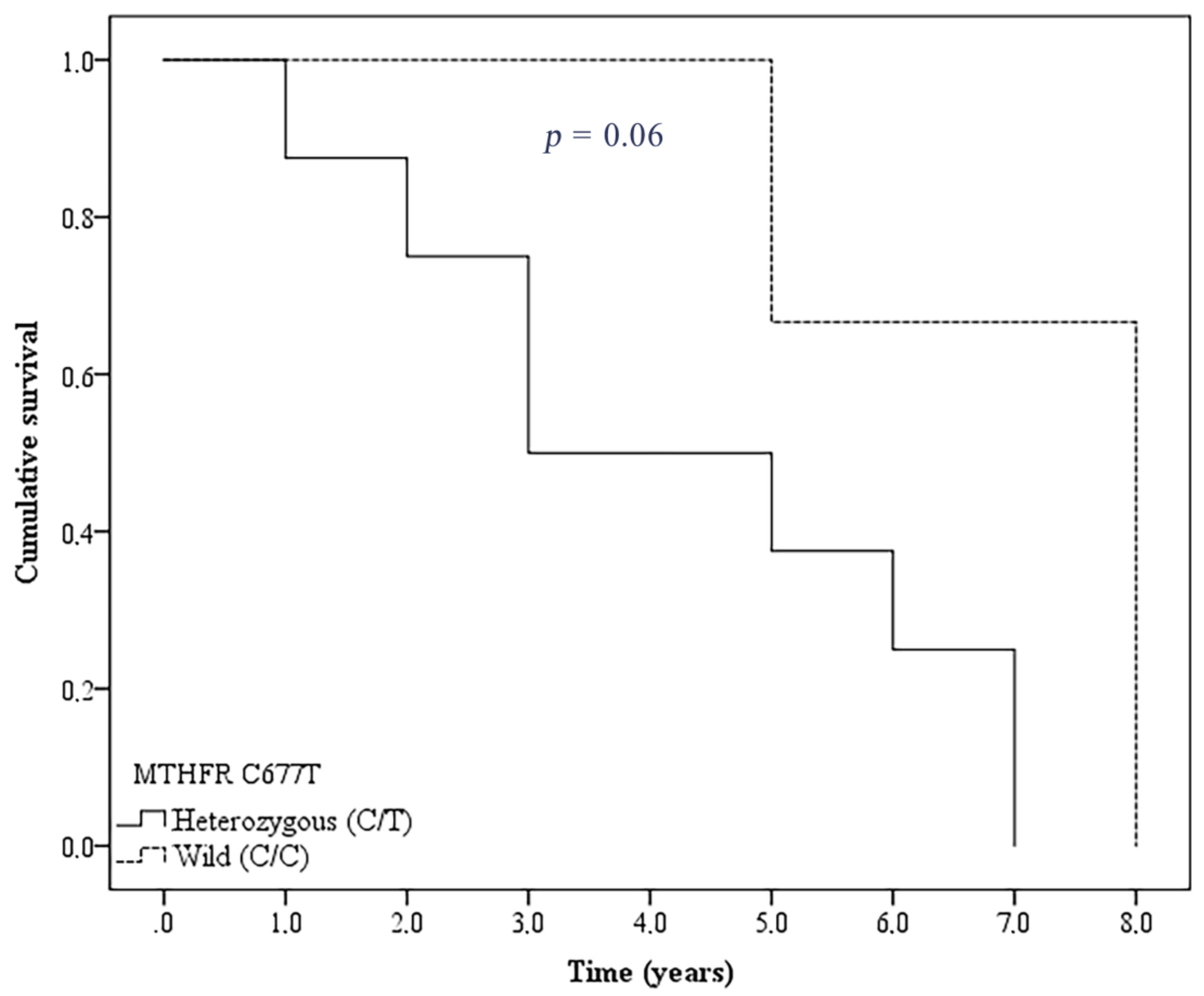

Figure 2

Kaplan-Meier curve analyzing survival at the onset of symptoms to outcome according to $(\mathrm{C} / \mathrm{C})$ and (C/T) MTHFR C667T polymorphism. 